\title{
Annual layers in river-bed sediment of a stagnant river-mouth area of the Kitagawa Brook, Central Japan
}

\author{
YOSHIMASA KURASHIGE ${ }^{1}$, TOSHIAKI NAKANO ${ }^{2}$, ERI KASUBUCHI ${ }^{3}$, \\ MASAHIRO MARUO ${ }^{1} \&$ HANAKO DOMITSU ${ }^{1}$ \\ 1 School of Environmental Science, The University of Shiga Prefecture, 2500 Hassaka-cho, Hikone 522-8533, Japan \\ kurashig@,ses.usp.ac.jp \\ 2 School of Environmental Science, The University of Shiga Prefecture, 2500 Hassaka-cho, Hikone 522-8533, Japan \\ 3 School of Education, Bukkyo University, 96 Kitahananobo-cho, Murasakino, Kita-ku, Kyoto 603-8301, Japan
}

\begin{abstract}
The river mouth of Kitagawa Brook is normally stagnant because it is easily closed by sand and gravel transported by littoral currents of Biwa Lake, Japan. A new urban area exists in the basin and sewerage works were constructed in the early 1990s, so contaminated water with a bad odour had flowed into the brook before the sewerage works. To reduce the smell, the river mouth was excavated to narrow the channel in the early 1980s. Thus, river-bed sediment after this excavation only occurs at the river mouth. From the upper $24 \mathrm{~cm}$ of a sediment core, we found 19 strata of leaves which were supplied from deciduous trees in autumn. We also found several gravel layers which were supplied from the lake during severe storms. The combination of veins and gravel layers were reconstructed for about 20 years of sediment records with an error of two to three years.
\end{abstract}

Key words river bed sediment; river mouth; stagnant area; stratigraphy; annual layer

\section{INTRODUCTION}

The Kitagawa Brook is a small brook which flows through the new urban area of Hikone City, and into Lake Biwa, the largest lake in Japan. Because of the littoral current of the lake, the mouth of the Kitagawa Brook is normally closed by sand and gravel, so it is stagnant. In addition, the river channel of the river-mouth area was artificially narrowed and meandered.

Sewerage works were started in the early 1990s and completed in 1998 in this urban area (Hikone City, 2013). Until the sewerage works, very contaminated water flowed into the brook, and the citizens of Ooyabu Town living around the river mouth had suffered from the very foul odour of the river water, particularly in summer. To take measures to cope with this situation, the local government excavated the river-bed sediment at the river mouth to narrow the water surface in the early 1980s (Mr. Iku Kitamura, a citizen of Ooyabu Town, pers. comm.). There is no official record of this alteration at Hikone City Hall.

If the river mouth area was actually excavated and narrowed in the early 1980s, the river-bed sediment in this area would have been deposited after the excavation. Also, the sedimentation that occurred before the sewerage works was when the river water was very much contaminated, whereas the new sediment deposited after the completion of the sewerage works settled under better water quality. Thus the sediment most likely reflects the history of river-water quality change.

The goal of our study is to reconstruct the history of river-water quality, with high accuracy over time, from the chemical components adsorbed on the sediment. For the first step, we checked the timing of the alteration from aerial photographs taken in different years, and compared it with information from citizens of Ooyabu Town. Further, for accurate reconstruction of environmental change, we tried to determine the annual layers from a sediment core.

To reconstruct the palaeoenvironment accurately, varved sediment is used as an annual layer, in particular for lake sediment (e.g. Amann et al., 2014; Corella et al., 2014). Varved sediment of a lake can be formed when laminations in sediment have developed due to qualitative and/or quantitative change of suspended sediment in a year (e.g. Strum, 1979), and these laminations are preserved in an appropriate lake bottom condition (e.g. Saarnisto, 1986). In this study area, however, such sediment may not exist, because the sedimentation conditions are very different from lake bottom conditions. A new method to find an annual layer representative of the river mouth area was thus developed in this study. 


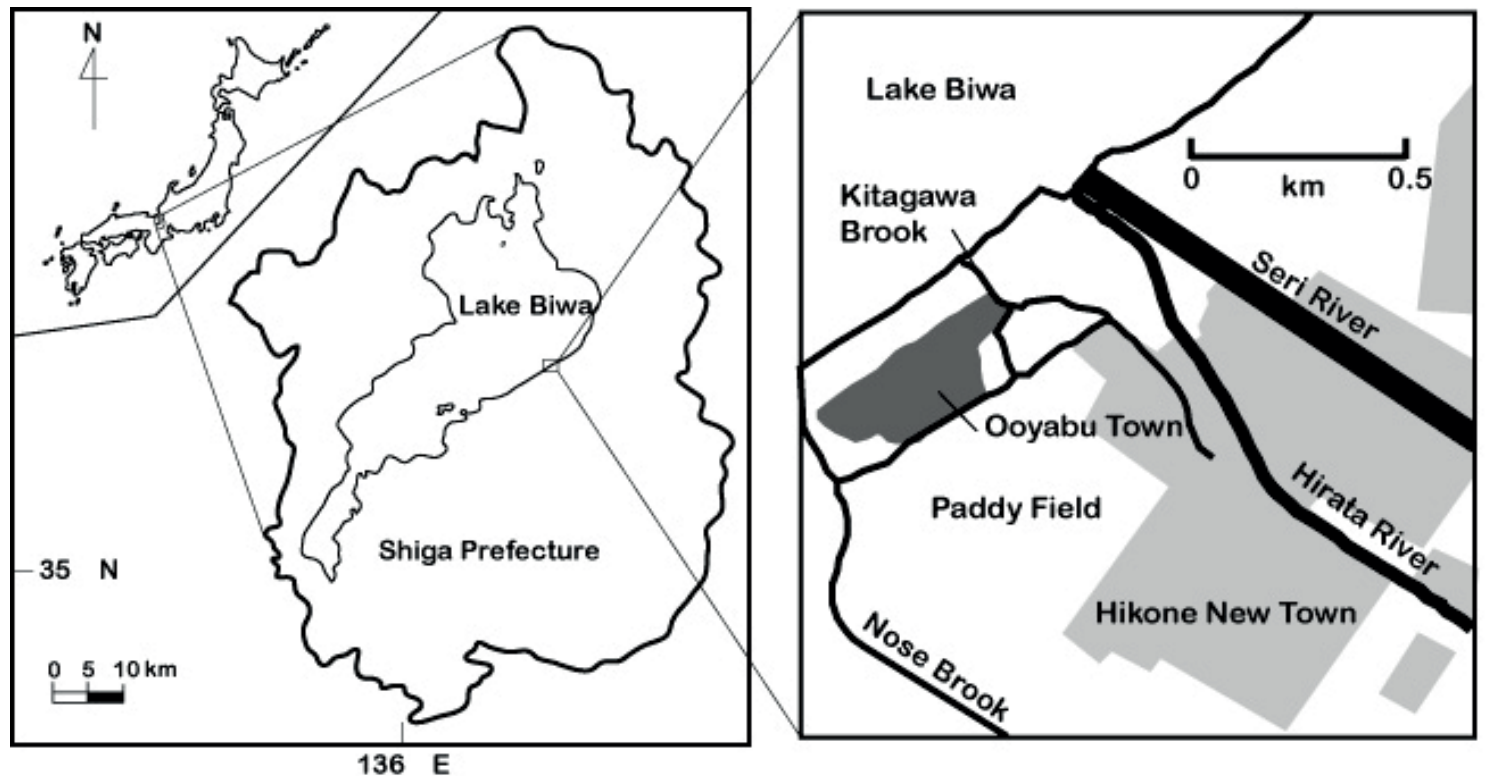

Fig. 1 Map of the study site.

\section{STUDY AREA}

The Kitagawa Brook starts from a spring in Hikone New Town, and flows through it to the surrounding paddy fields, and then into Lake Biwa at the northern end of Ooyabu Town (Fig. 1). The distance from the spring to the river mouth is about $1 \mathrm{~km}$. Some distributaries flow from the brook, and one of them flows into the Nose Brook which flows southwest of Ooyabu Town. Two rivers (the Hirata and the Seri) flow northeast of the brook, which does not join these rivers.

Both the river bed and river bank are covered with concrete from the spring to $180 \mathrm{~m}$ upstream of the river mouth, whereas the river bed of the lower reach is covered with mud, sand and pebbles. At the altered reach, in contrast, little sediment could be found on the river bed. Trees can be found around the river mouth area, whereas none exist around the concrete-covered reach.

Hikone New Town was developed in the 1970s. The area was composed mainly of paddy fields before the development. Many houses started to be constructed in the 1970s, so the population in this area increased hugely from 1975 to 1980 (Hikone City, 1982), and even into the early 1980s (Hikone City, 1988). A drain system was constructed in the new town, and was directly connected with the Kitagawa Brook, so wastewater from the new town directly entered Kitagawa Brook. Further, the sewerage works operation started in 1993 and finished in 1998 in and around the new town (Hikone City, 2013). After this work, the wastewater was managed at a sewage plant in Hikone City. The wastewater thus no longer flowed into the brook after 1998.

Hikone City has monitored the river-water quality of the Kitagawa Brook around the study area once a month since 1984. As an example, the temporal variation of the annual average of total phosphorus (T-P) is shown in Fig. 2 (data source: Environmental Division, Hikone City, pers. comm.). The concentration of T-P drastically decreased from 1993 to 1999. This coincides with the timing of the sewerage works provided in the Hikone New Town (1993 to 1998).

In contrast, Ooyabu Town is a very old town dating back to the 19th century (Hikone City, 2002). It is located on a littoral ridge formed by a southwestward littoral current of Lake Biwa (Uda and Nishijima, 1998). As the town is on the ridge, its relative height is about $1 \mathrm{~m}$ higher than the paddy fields which still exist between the new town and Ooyabu Town.

The river mouth of the Kitagawa Brook is located at the northernmost part of Ooyabu Town. The brook cuts through the littoral ridge and flows into Lake Biwa. The river mouth is easily closed by sand and gravel transported by the littoral current of the lake, so the river water just upstream of the river mouth is normally stagnant. 


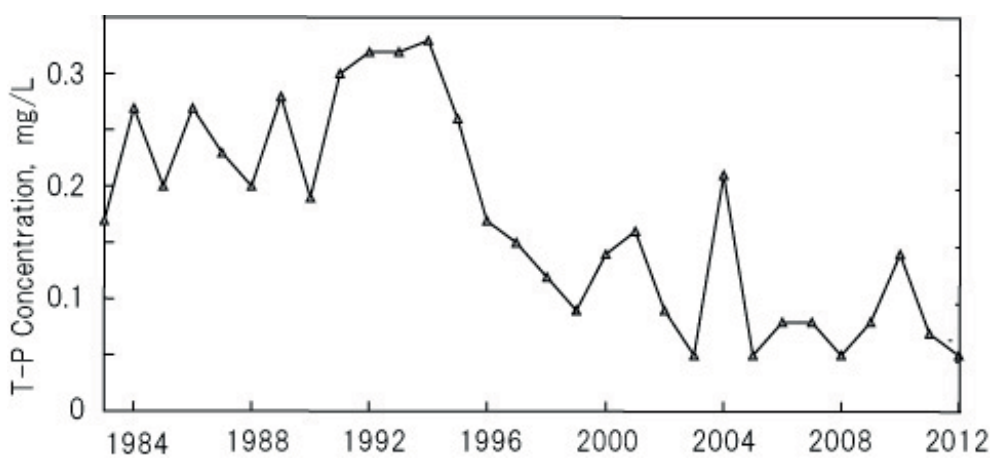

Fig. 2 Annual variation of total phosphorus dissolved in the river water of the Kitagawa Brook. Data source: Environmental Division, Hikone City.

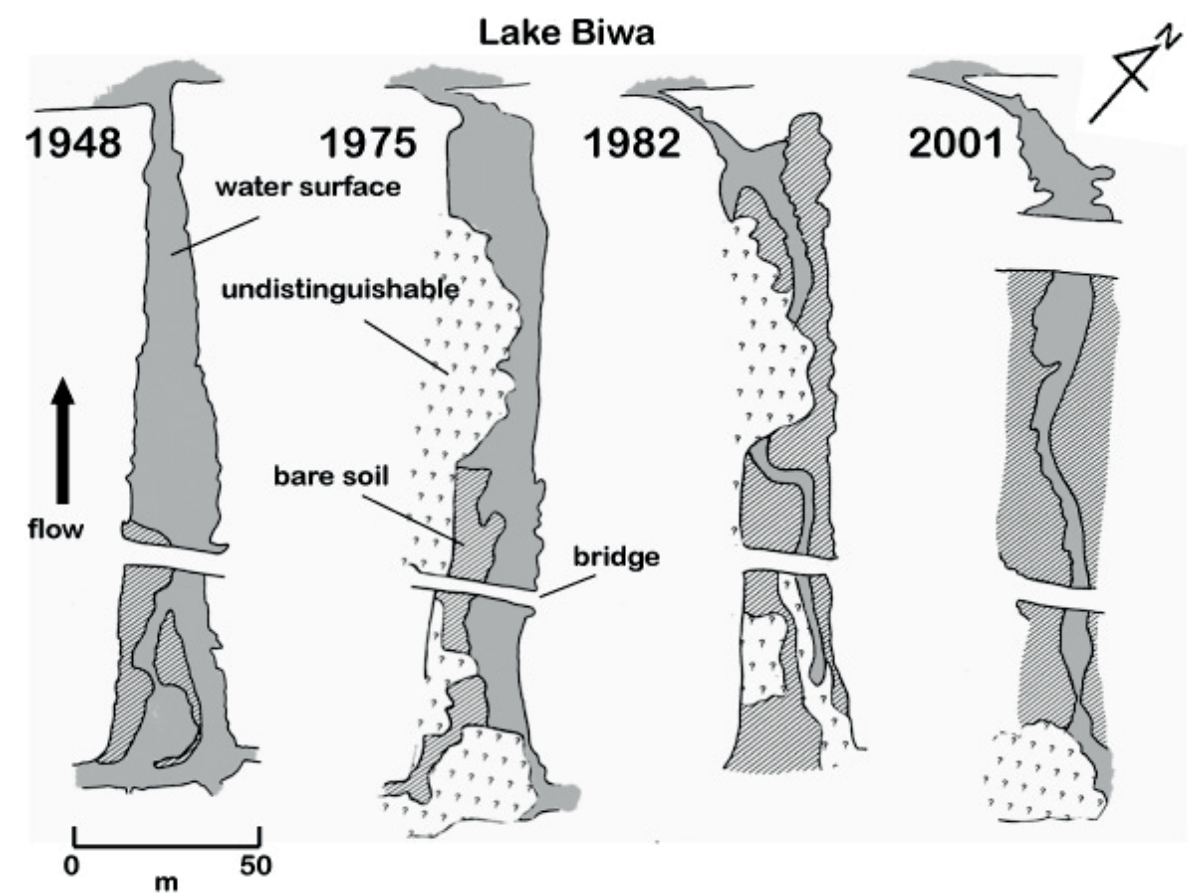

Fig. 3 Geomorphological maps of the river mouth area of Kitagawa Brook in 1948, 1975, 1982 and 2001. The maps were traced from aerial photographs obtained from the Geospatial Information Authority of Japan.

\section{ALTERATION AROUND THE RIVER MOUTH}

Figure 3 shows geomorphological maps of the river mouth of the Kitagawa Brook in four different years. The maps were traced from aerial photographs distributed from the Geospatial Information Authority of Japan. In some cases, the ground surface could not be seen on the photograph due to the thick tree growth, so such areas are marked with question marks on the maps. Both in 1948 and 1975 , a wide water surface could be seen, whereas only a narrow channel existed in 1982, showing that the brook was altered before 1982. Bending existed 20 to $30 \mathrm{~m}$ downstream of a bridge, whereas this bending could not be seen in 2001, showing that the channel was again altered in the reach downstream of the bridge between 1982 and 2001.

We asked Messrs Sakuhei Kitamura, Iku Kitamura and Hisao Hori, ex-officials of the Residents' Association of Ooyabu Town, about the alteration of the brook. They told us that it was altered in 1981 around the river mouth. The river bed was excavated to narrow the width of the channel. In addition, the channel was artificially meandered and the side of the channel was covered with pine posts. After this alteration, new land was formed both on the right and left banks of the new channel. In summer, the new land was overgrown with weeds, so the citizens had to 
weed the new land. This hard work created a new problem for the citizens, and the Residents' Association petitioned the mayor of Hikone City to prevent the weeds. Work to prevent weeds was done from 1999 to 2003, and the ground surface of the new land was covered with concrete, and the concrete surface was gravelled.

The information from the ex-officials showed that the brook was altered in 1981 around the river mouth, which coincides with the data from the aerial photographs. However, the information did not mention about the re-alteration between 1982 and 2001. The new land formed by the excavation of the brook was, however, under construction from 1999 to 2003, so we presume that the channel may have been re-altered between 1999 and 2001, downstream of the bridge.

\section{STRATIGRAPHY OF THE RIVER BED SEDIMENT}

A sediment core was sampled in October 2012 about $30 \mathrm{~m}$ upstream of the bridge. A large deciduous tree exists at the left bank of the sampling site. A vinyl chloride cylinder of $5.8 \mathrm{~cm}$ diameter and $90 \mathrm{~cm}$ length was inserted into the river-bed sediment by hand, until the cylinder touched the lower hard sediment. The cylinder could be inserted to about $50 \mathrm{~cm}$ depth. River water was poured into the cylinder and its top end was covered with a cap. The cylinder was then pulled out slowly from the sediment, and the bottom end of the cylinder was also covered with a cap. The top cap was then opened, and the water in the cylinder was drawn off by a siphon. The space in the cylinder was filled with rags to prevent the sediment from moving, and again the top end was covered with the cap.

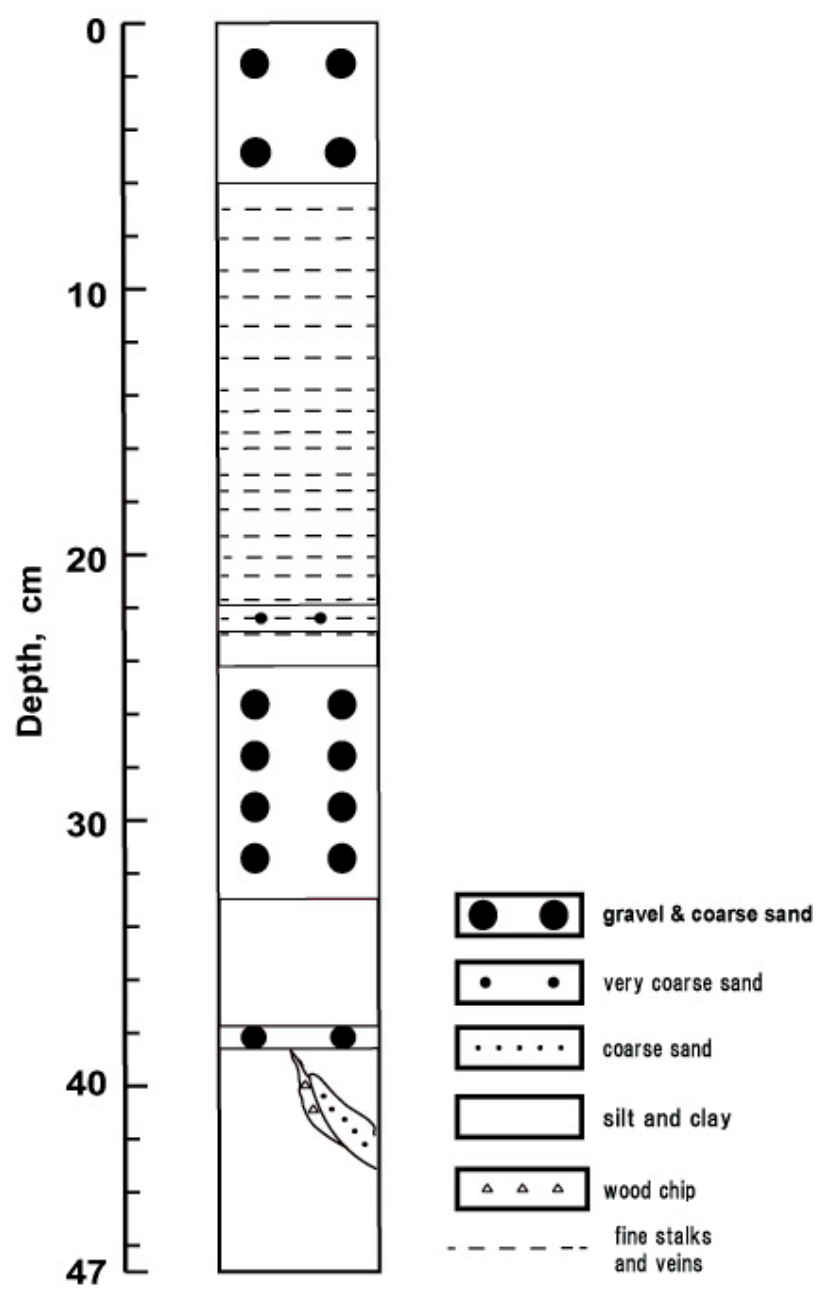

Fig. 4 Stratigraphy of the sediment core sample. 
The cylinder was carried to a laboratory to be cut longitudinally into two. The cylinder side was first cut with a cutter, and then the sediment inside was cut with fishing gut. The sections were carefully observed to sketch the precise stratigraphy of the sediment. Figure 4 shows the stratigraphy of the sediment sample. The sediment was mainly composed of silt and clay, whereas three strata of coarse sand and gravel $(0-6 \mathrm{~cm}, 24-33 \mathrm{~cm}$ and about $38 \mathrm{~cm}$ deep) were also found. In particular, the top stratum contained pebbles. At 40-45 cm deep, an inclined stratum of coarse sand was also found. Several pieces of wood were present from 39 to $43 \mathrm{~cm}$ depth. This layer with wood pieces was inclined, and adjacent to the inclined coarse sand stratum. Precise observation using a magnifying glass of 22 magnifications revealed that fine stalks and veins of leaves were accumulated in 19 strata (dashed lines in Fig. 4).

\section{DATING OF STRATA}

\section{Dating from gravel layer}

Two thick sand-and-gravel layers (i.e. $0-6 \mathrm{~cm}$ and $24-33 \mathrm{~cm}$ ) were found in the sample (Fig. 4). We could not find such gravel in the upper altered reach of the brook. The gravel could be found only in the lowermost reach of the brook. However, lake shore sediment contains coarse sand and gravel, and this coarse sediment normally closes the river mouth. This indicates that the lake shore sediment is most likely to be the source of gravelly sediment in the core.

To determine the origin of the pebbles, we sampled all pebbles larger than $2 \mathrm{~mm}$ from the top 0-6 cm layer of the sample (108 pebbles), and measured the flatness of each pebble as defined by Wentworth (1919). The lake shore sediment was also randomly sampled from the river mouth, and 135 pebbles were sampled from the shore sediment. The flatness of the shore pebbles was also measured. The pebbles in the core-top sample had an average flatness of 1.93, and the standard deviation was 0.54 . The shore pebbles averaged 2.04 with a standard deviation of 0.55 . The MannWhitney $U$-test could not detect a significant difference between these two samples.

Ran (2014) also measured the flatness of the lake shore $2-5 \mathrm{~mm}$ pebbles sampled about $1 \mathrm{~km}$ southwest of the river mouth, and reported their average flatness of 2.06 with a standard deviation of 0.61 . He also measured the flatness of river-bed pebbles of the same size sampled at the lowermost reach of the Inukami River, which flows into the lake about $1 \mathrm{~km}$ southwest of this study area. The flatness of the river-bed gravel was on average 1.81, standard deviation of 0.48 . These results also indicate that the origin of the core-top gravel is the lake shore sediment.

Since the Kitagawa Brook flows into Lake Biwa in a northwest direction, the lake shore gravels are most likely to be transported into the river-mouth area only when high waves are induced by a strong northwestward wind. We searched the database of the Japan Meteorological Agency (2013), which defines a "strong wind" as a 10-minute average wind speed exceeding 15 $\mathrm{m} / \mathrm{s}$, for events of strong northwestward wind observed at Hikone Local Meteorological Office from 1981 to 2012. We could find only the following three events: 30 September $2012(16.6 \mathrm{~m} / \mathrm{s}$ due to Typhoon 17 of 2012), 8 October $2009(15.5 \mathrm{~m} / \mathrm{s}$ due to Typhoon 18 of 2009) and 20 September $1990(16.6 \mathrm{~m} / \mathrm{s}$ due to Typhoon 19 of 1990$)$.

In addition, if the lake water level is low, the water level of the river mouth area will be higher than the lake water level, because the river mouth is easily closed by sandy gravel. In such a condition, a lake wave would hardly enter the river mouth area even if strong wind occurs. We thus checked the lake water level during these three events using the lake water-level data personally provided from the Biwako Office of Kinki Regional Development Bureau, Ministry of Land, Infrastructure, Transport and Tourism, Japanese Government. The lakewater level was $+0.72 \mathrm{~m}$ from BSL (Biwako Surface Level, i.e. standard water level of Lake Biwa, $84.371 \mathrm{~m}$ a.s.1.) on 30 September 2012, $-0.38 \mathrm{~m}$ on 8 October 2009 and $+0.44 \mathrm{~m}$ on 20 September 1990.

Since the core sample was taken in October 2012, the sand-and-gravel of the top 0-6 cm can be judged to have been deposited during an event just before the sampling day. This layer was thus concluded to have been deposited during the event of 30 September 2012, showing that the northwestern wind of $16.6 \mathrm{~m} / \mathrm{s}$ and BSL $+0.72 \mathrm{~m}$ had sufficient power to transport the lake shore gravel. 
The gravel layer at 24-33 cm had a thickness larger than the top gravel layer, indicating a strong wind event of a magnitude the same or larger than the event on 30 September 2012. The wind speed on 8 October $2009(15.5 \mathrm{~m} / \mathrm{s})$ was lower than that on 30 September 2012, and the lake water level on this day was low (BSL $-0.38 \mathrm{~m}$ ), indicating this thick gravel layer was not deposited during this event. In contrast, the event on 20 September 1990 had a wind speed equal to that on 30 September 2012. The lakewater level on 20 September 1990 (BSL $+0.44 \mathrm{~m}$ ) was lower than that on 30 September 2012, whereas it was much higher on 8 October 2009. In addition, the Japan Meteorological Agency (2013) shows a maximum wind speed on 20 September 1990 of $29.3 \mathrm{~m} / \mathrm{s}$, whereas that on 30 September 2012 was $23.8 \mathrm{~m} / \mathrm{s}$. It was thus concluded that the gravel layer at 24-33 cm was deposited during the event on 20 September 1990.

\section{Dating from layer of fine stalks and veins of leaves}

Fallen leaves from deciduous trees covered the river bed of the river mouth area in November 2012. Continuous observation of the river bed revealed that this cover of fallen leaves could be found in March 2013, but not in early May 2013. Ploughing before transplanting rice seedlings was done in the paddy field just upstream of the river-mouth area and very turbid water flowed into the brook in late April 2013, so new silt and clay sediment was considered to have been deposited over the leaves on the river bed. Further, the leaves were most likely to be decomposed by chemical and/or biological activities at the site, particularly in summer. Fine stalks and veins were considered to not decompose well, and to remain where they fell. Thus, the layers of fine stalks and veins were considered to show the late autumn level.

The uppermost stalk layer was found at $7 \mathrm{~cm}$ depth in the core sample, only $1 \mathrm{~cm}$ below the top gravel layer. The uppermost stalk layer was thus determined as deposited in late autumn 2011. Since 19 strata of stalk layer were found, the lowest stalk layer at $23 \mathrm{~cm}$ depth was determined as having been deposited in autumn of 1993, if all stalk layers were preserved in the sediment.

Since the gravel layer of $24-33 \mathrm{~cm}$ was determined as deposited in September 1990, the siltand-clay layer of 23-24 cm deep would have been deposited just after the event in September 1990 , i.e. deposited in 1990. If we missed finding a stalk layer of 1990, this silt-and-clay layer can be determined to have been deposited in 1991. This indicates that the determination of the annual layer in this study has an error of 2 to 3 years.

\section{DISCUSSION AND PERSPECTIVES}

The age of sediment was determined at layers after 1990 with an error of 2 to 3 years. In contrast, the age could not be determined for the layers lower than the $33 \mathrm{~cm}$ depth in the core. Stalk layers were not found deeper in the core, and no meteorological event could be found to have formed the gravel layer at $38 \mathrm{~cm}$ depth.

Two inclined layers were found below the $38 \mathrm{~cm}$ depth, indicating that this sediment was disturbed. However, the layers above $24 \mathrm{~cm}$ depth indicate that $18 \mathrm{~cm}$ of silt and clay sediment were deposited in 22 years, showing that the average sedimentation rate was about $0.8 \mathrm{~cm} /$ year. If the sedimentation rate is the same for the layers lower than $33 \mathrm{~cm}$, the layers deeper than $38 \mathrm{~cm}$ depth were deposited before 1984, and the sediment at the bottom of the core sample was deposited in the early 1970s. The river channel was excavated in 1981. The lowest part of the core sample was judged to have been deposited before 1981. In addition, the sediment older than 1981 was no doubt disturbed during the excavation operation. The lowest part was considered to be sediment deposited before the excavation in 1981.

The layer between 33 and $39 \mathrm{~cm}$ deep was not disturbed, but fine stalks and veins could not be found from this layer. The reason is still unknown, but we suppose that the decomposition process of stalks and veins may have affected their disappearance.

In contrast, the age of the upper layer could be determined with high accuracy. This indicates that chemistry of sediment may record the change in the water quality of the brook, particularly when it changed drastically after 1990. Also, the water quality data of the brook can be compared with the chemistry of the sediment. 
Furthermore, the method to find annual layers obtained in this study could be applied to other river-mouth areas of small brooks in temperate zones where deciduous trees are dominant. In this study, the stalk layers are well preserved for about 20 years due to sedimentation of suspended sediment flowing during ploughing before transplanting rice seedlings in paddy fields. If the rivermouth area is under such conditions, this can be used as a new method to find annual layers.

Acknowledgements We acknowledge Dr Wayne Erskine for helpful comments and kind editorial assistance. This study was partly supported by JSPS KAKENHI Grant No. 24650605.

\section{REFERENCES}

Amann, B., Mauchle, F. \& Grosjean, M (2014) Quantitative high-resolution warm season rainfall recorded in varved sediments of Lake Oeschinen, northern Swiss Alps: Calibration and validation AD 1901-2008. Journal of Paleolimnology, 51, 375-391.

Corella, J.P., et al. (2014) Annually-resolved lake record of extreme hydro-meteorological events since AD 1347 in NE Iberian Peninsula. Quaternary Science Reviews, 93, 77-90.

Hikone City (1982) Report of the Results of National Census 1980, Hikone City (in Japanese).

Hikone City (1988) Report of the Results of National Census 1985, Hikone City (in Japanese).

Hikone City (2002) Old maps of Hikone in Meiji Period 2, Editorial Committee of History of Hikone City (in Japanese).

Hikone City (2013) Plan of Public Sewer System of Hikone City, Hikone City (in Japanese).

Japan Meteorological Agency (2013) Meteorological Data. Home Page of Japan Meteorological Agency. http://www.data.jma.go.jp/obd/stats/etrn/index.php (accessed 27 September 2013) (in Japanese).

Ran, X (2014) Topographical change of these ten years at river-mouth area of the Inukami River. MSc Thesis, The University of Shiga Prefecture, Hikone, Shiga, Japan (in Japanese).

Saarnisto, H. (1986) Annually laminated sediments. In: Handbook of Holocene Pleohydrology. (ed. by B.E. Berglund), 343370. John Wiley \& Sons, Chichester, UK.

Strum, M, (1979) Origin and composition of clastic varves. In: Moraines and varves: origin, genesis, classification. (ed. by Schlucher, C.), 281-285. Proceedings of an INQUA symposium on genesis and lithology of Quaternary deposits, Zurich.

Uda, T. \& Nishijima, T. (1998) Littoral vegetation limit and drift sand in lake under wind wave. In: Geomorphology and conservation of waterfront environment (ed. by Japanese Geomorphological Union), 112-147, Kokon-shoin (in Japanese).

Wentworth, C.K. (1919) A laboratory and field study of cobble abrasion. Journal of Geology, 27, 507-521. 